\title{
Apoio e acolhimento à mulher que se torna mãe: uma escuta psicanalítica*1
}

Alcimeri Kühl Amaral Veiga Prata*2

Elisa Maria de Ulhôa Cintra*3

A proposta deste artigo é apresentar um modelo de escuta endereçado a questões que envolvem a maternidade. Para construir esse espaço de escuta psicanalítica no âmbito institucional, foi preciso, inicialmente, ampliar a compreensão das vicissitudes do processo que envolve o ser mãe. Um método respaldado no amparo e no acolhimento foi o modelo utilizado no atendimento de mulheres que estavam com os seus bebês internados na Unidade de Terapia Intensiva Neonatal (UTIN). A partir do caso exposto, foi possível apresentar um modelo de escuta que se fundamenta no referencial psicanalítico, mas que, ao mesmo tempo, amplia o modelo tradicional da psicanálise.

Palavras-chave: Escuta psicanalítica, maternidade, relação mãe-bebê, apresentação de caso

${ }^{* 1}$ Este artigo é derivado da dissertação de mestrado de Alcimeri Kühl Amaral Veiga Prata, sob orientação de Elisa Maria de Ulhôa Cintra.

*2 Pontifícia Universidade Católica de São Paulo - PUC-SP (São Paulo, SP, Br).

${ }^{* 3}$ Pontifícia Universidade Católica de São Paulo - PUC-SP (São Paulo, SP, Br). 


\section{ARTIGOS}

\section{Introdução}

A mulher que se torna mãe passa por uma gama de sentimentos difusos em virtude de vivenciar uma fase de grandes transformações: no corpo, na vida social e na psique. O modo como cada uma experimentará esse período de transformação está diretamente relacionado à sua história pessoal prévia e também ao contexto particular no qual a gravidez se insere. Diante de tantos fatores - de ordem interna e externa - não é incomum que a própria gestação, e posteriormente o nascimento do bebê, causem rupturas psíquicas que podem levá-la a viver uma experiência de tristeza, insegurança, desânimo e desamparo. Essas ocorrências e o sofrimento psíquico que se instala não estão necessariamente vinculados à gestação e ao nascimento do filho, mas podem ter suas raízes em fatos antecedentes ocorridos na vida da mulher.

O sofrimento psíquico pode, nesse sentido, ser fruto de experiências traumáticas não simbolizadas; estar ligado a fracassos de um ideal de realização; a lutos não elaborados; ou, ainda, a alguma turbulência emocional que se instala de forma abrupta. Por outro lado, esse tipo de situação pode fazer eclodir conflitos intrapsíquicos que estavam velados, tornando o sujeito vulnerável não apenas à circunstância emergente, como também a toda uma experiência anterior não simbolizada. $\mathrm{O}$ papel do psicanalista, independentemente do contexto do atendimento, é o de proporcionar uma terapêtica que abra possibilidades para o sujeito dar sentido à sua vida e às vicissitudes de sua existência. Trata-se de oferecer uma experiência integradora para que, a partir dela, ele possa recuperar os objetos perdidos dentro de si. Tais objetos são os registros das experiências emocionais vividas, sendo que o par cuidador-cuidado pode ser a representação de um objeto bom internalizado.

Quando o psicanalista se propõe a escutar o outro, ouvir o seu sofrimento, acolher sua angústia, amparar seu desespero e guiá-lo pelo seu desamparo é porque acredita que existe um sujeito do inconsciente que possui potencialidades integrativas. Muito provavelmente existe um sujeito perdido em suas dores, mas que pode se beneficiar de uma escuta acolhedora. A dor falada solicita escuta. A escuta psicanalítica possibilita 


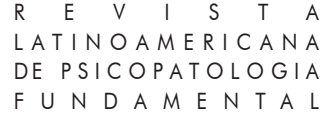

que a dor seja transformada em experiência. A experiência real permite a elaboração da experiência emocional.

Diante de tais colocações, considerando que a instauração da maternidade pode vir acompanhada de rupturas emocionais, defendemos que a escuta psicanalítica pode (e deve) estar presente nos mais variados contextos institucionais, inclusive para a questão da maternidade, contemplando suas implicações, seus limites e sua técnica. $\mathrm{O}$ caso $^{1}$ relatado a seguir, atendido em contexto hospitalar, ilustra como essa modalidade de clínica pode estar presente dentro de uma maternidade. O serviço de psicologia do hospital em que essa paciente foi atendida propunha-se a oferecer uma acolhida e uma escuta terapêutica às mães, aos pais e familiares que estavam com seus bebês internados na UTIN (Unidade de Terapia Intensiva Neonatal). A equipe de psicologia era formada por profissionais de diferentes áreas de atuação que trabalhavam em prol de um objetivo comum: oferecer apoio psicológico às mais diversas situações que acometem mães, pais e familiares usuários da maternidade do hospital.

\section{Compreender o ataque como defesa extrema: da violência ao abraço}

Os eventos que culminaram no primeiro atendimento de Betânia ${ }^{2}$ foram um tanto quanto atípicos. Logo ao chegar ao hospital naquela manhã, havia um pedido de "atendimento urgente" para uma puérpera que havia dado à luz há um dia. Procurei inteirar-me do que estava ocorrendo por meio do prontuário e também conversando com a equipe de profissionais que estiveram em contato com a paciente.

Betânia havia sido atendida no dia anterior por um psiquiatra do hospital, o qual indicou-lhe acompanhamento psicológico. Esse profissional havia sido chamado após uma sequência de eventos nos quais Betânia insultou as enfermeiras, gritou e bradou com o médico e profissionais da UTIN, apresentando comportamento marcado por exacerbada inquietude e ansiedade.

\footnotetext{
${ }^{1}$ Para uma leitura mais detalhada deste e de outros casos, cf.: Prata, Alcimeri Kühl Amaral Veiga (2016), Apoio e sustentação ao desamparo materno: uma escuta psicanalítica. Dissertação de mestrado, Pontifícia Universidade Católica de São Paulo - PUC-SP, São Paulo, SP.

${ }^{2}$ Os pormenores da história, personalidade, nome, idade e outras circunstâncias que de alguma forma pudessem identificar os envolvidos, foram alterados ou omitidos para proteger sua identidade.
} 


\section{ARTIGOS}

Diante de um pedido de urgência e com um quadro tão emblemático, tentei seguir a orientação de Freud (1912/2006a) e abster-me das possíveis interferências negativas que poderiam sobrepujar o atendimento e criar uma preconcepção da mulher que estava prestes a conhecer. Tarefa esta nada fácil diante do bombardeio de relatos negativos a seu respeito.

Fui recebida por Betânia com muita hostilidade, chegando inclusive a temer por minha segurança nos primeiros dez ou quinze minutos do atendimento. Negando completamente sua fragilidade, parecia que essa recém-mãe fazia uso de defesas muito primitivas. Seu comportamento era agressivo, gritava e apontava o dedo no meu rosto, vociferava que eu também achava que ela era louca e que nunca poderia entender o que ela estava passando. Diante de uma angústia persecutória tão acentuada, apenas tentei permanecer aberta para a possibilidade de compreender minimamente o que estava ocorrendo, e logo descobri que Betânia estava se sentindo completamente desamparada e insegura. Seu comportamento agressivo tinha um único intuito: comprovar que eu também me afastaria. Mas não fui embora, fiquei, ouvi, acolhi.

Pensando na orientação que Winnicott (1971/1984) expressa em seu trabalho Consultas terapêuticas em psiquiatria infantil de que uma única sessão pode ser organizadora para o paciente, procurei ficar o mais disponível possível para Betânia. Contudo, uma pergunta insistia em rondar meus pensamentos: "O que eu posso fazer por você?". Em um primeiro momento a única resposta para essa autoindagação era a de que eu precisava ouvi-la, precisava estar ali com ela e para ela. Dessa forma o primeiro atendimento durou um pouco mais de três horas. Escutei sua história, tentando me abster ao máximo de qualquer pré-diagnóstico.

A gravidez de Betânia foi, segundo ela, um "acidente planejado". Aos 31 anos de idade e com uma história de bipolaridade há mais de 15, Betânia disse estar cansada de ser apontada como louca e desequilibrada. Entendeu que talvez a maternidade pudesse lhe trazer um pouco de credibilidade para as pessoas que conviviam com ela, especialmente sua própria mãe. Nas últimas férias decidira fazer uma viagem a uma região litorânea. Sabendo que estava em seu período fértil, resolveu "arriscar". Obteve sucesso em seu intuito, engravidando de um homem que conhecia muito pouco e com o qual não voltou a ter contato desde essa breve relação.

A gestação, que apresentava certo risco por conta do uso contínuo de medicamentos psiquiátricos e por ser uma fumante inveterada, deveria ter sido acompanhada muito de perto por um obstetra de confiança. Entretanto, foi muito difícil para Betânia vincular-se a algum médico. Passou por vários profissionais durante a gestação, mas acabou realizando o parto com a equipe 


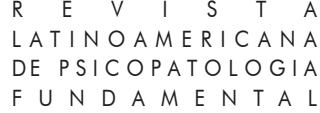

plantonista do hospital. Comecei a perceber que algo se repetia na história dessa mulher: pessoas estranhas, desconhecidas, pareciam vir ampará-la em situações-limite. Talvez isso ocorresse pelo fato de Betânia apresentar uma grande dificuldade de estabelecer vínculos.

Vou ouvindo essa mulher que se apresentava de forma tão hostil e encolerizada, exalando fúria e agressividade, mas que me pareceu tão desolada, desamparada e desorientada, que resolvi fazer algo pouco usual. Disse a ela que via muita dor e sofrimento no que me contava, e tudo o que poderia the oferecer naquele momento era a minha escuta livre de qualquer julgamento. Estendi meus braços e perguntei: "você aceita?". O que eu propunha naquele momento era instalar minimamente um ambiente facilitador ou um ambiente favorável (Winnicott, 1963/1983c) para que minha paciente pudesse começar a sentir física e emocionalmente o que estava se passando à sua volta, mas principalmente o turbilhão de afetos em seu mundo interno. Minha atitude era a de poder oferecer-lhe uma alternativa ao desamparo. Inicialmente, ela surpreendeu-se com o meu gesto, inibindo-se por um momento e aceitando o abraço. Senti que estava muito tensa e seu abraço era quase mecânico, mas, pouco tempo depois, relaxou o corpo e se deixou ser acolhida, irrompendo em um choro sentido.

38 Betânia sempre sentiu uma solidão avassaladora, nunca teve nenhuma grande amiga ou qualquer outra pessoa com quem pudesse dividir suas alegrias e inquietações. A relação com a mãe era marcada pela ambivalência. Era muito difícil saber, no âmbito das sessões de escuta psicanalítica, como mãe e filha construíram essa relação marcada pela desconfiança, rancor e cobranças. Mas, pensando no que Klein (1940/1996c) e Winnicott (1971/1989) defendem sobre as experiências precoces e um ambiente que permita o desenvolvimento saudável - que é diferente de um desenvolvimento livre de doenças psíquicas -, podemos pensar que Betânia talvez tenha introjetado um ambiente hostil, que a tornou uma pessoa tempestuosa e tensa em resposta a esse ambiente. Muitas brigas e discussões sempre estiveram presentes entre mãe e filha. Diante dessas colocações, fui construindo, conjuntamente com ela, o lugar que o filho ocuparia em sua vida.

É esperado que, após o nascimento, o filho venha renarcisar a mulher, agora reconhecida como mãe (Freud, 1914/2006b; Druon, 2011). Entretanto, para o bebê de Betânia, o que cabia era a grande tarefa de curar a ferida narcísica da mãe, ferida esta que, provavelmente, estava aberta desde sua própria experiência em ser cuidada. O filho veio para ocupar o lugar dessa pessoa especial com quem poderia contar e confiar. Quando ela conseguiu dar voz a essa "enxurrada" de afetos contidos, sentiu-se constrangida e envergonhada: "como eu posso querer tanto de um bebê tão frágil e indefeso?". Era o reconhecimento de que o filho 


\section{ARTIGOS}

precisava ser cuidado e amparado por ela. Por outro lado, Betânia também tinha a necessidade de ser cuidada. Aos poucos, quando foi se permitindo entrar em contanto com sua fragilidade e seus desafios, foi ficando claro para ela o quanto seu bebê também precisava ser acalentado no colo da mãe, junto ao seu corpo, sentindo os ritmos de seu coração e de sua voz. O bebê precisava muito dessa continuidade do que vivia no útero, dessa relação simbiotizada, desse lugar de existência e de continuação do seu ser (Freud, 1926/2006c; Winnicott, 1966/2006; Fontes, Roxo, Soares \& Kislanov, 2014).

O pequeno Pedro nasceu na $36^{\mathrm{a}}$ semana de gestação, pesando um pouco menos de dois quilos. Precisou de auxílio para respirar e, por isso, foi encaminhado à UTIN. A primeira visita de Betânia ao filho, que ocorreu antes do atendimento psiquiátrico e psicológico, foi extremamente conturbada, e toda a equipe da UTIN estava receosa de recebê-la novamente. Na segunda visita, que aconteceu no mesmo dia do primeiro atendimento psicanalítico, acompanhei mãe e filho nesse encontro. Até aquele momento Betânia estava desamparada, seus gritos não eram ouvidos, não havia nenhum cuidador presente no real da cena ou preservado simbolicamente em sua realidade psíquica. Foi a partir de uma escuta, que ouviu para além dos gritos e da agressividade, que Betânia pôde começar a sentir a dor - física e psíquica — do parto.

Interessante perceber que, embora fizesse pouco mais de 24 horas que Betânia havia sido submetida a uma cesárea, movimentava-se com uma desenvoltura muito além do esperado para uma puérpera. Contudo, após falar um pouco de si, de suas angústias, medos e apreensões, ela pôde dar lugar à dor física que uma cirurgia cesariana tende a causar. Essa ressalva se faz necessária porque, mostrando-se mais fragilizada e necessitando de cuidados, ela pôde pedir para utilizar a cadeira de rodas para ir até a UTIN, o que não havia ocorrido no dia anterior, causando estranhamento aos profissionais. Suponho que a defesa maníaca que imperava até o nosso encontro blindava seu corpo das dores e desconfortos físicos.

A cena do encontro (sim, encontro, pois foi a primeira vez que Betânia de fato percebeu e recebeu seu filho) foi tocante. Uma mulher calma e preocupada tocava o corpo do bebê enquanto declamava palavras doces carregadas de afeto. Acredito que foi a partir daquele momento que essa mãe pôde começar a garantir a continuidade da existência do seu filho. Pedro, antes de poder se separar, precisava da continência de um colo que entendesse como a continuação do seu próprio eu, de alguém que pudesse dar bordas para uma sensação de liquefação que sentiria nos primeiros meses de sua vida (Winnicott, 1962/1983b; Fontes et al., 2014). 
Meu papel naquele momento era apenas de testemunha, muito embora reconheça que provavelmente para Betânia tenha sido importante a figura de um outro que a apoiasse, caso fosse necessário. Mãe e bebê começavam ali, naquele momento, a estabelecer laços. $\mathrm{E}$ eu, diante desse espetáculo da maternidade, via desabrochar um potencial de amor materno que, antes, estava mascarado pela hostilidade e incompreensão. Esse amor materno, que como sabemos é uma construção que acontece na relação mãe-criança (Hilferding, 1911/1991; Klein, 1957/1974; Lima, 2006; Figueiredo, 2014), estava em iminência de sucumbir caso Betânia não conseguisse equilibrar o turbilhão de afetos que a invadiam. Inicialmente, sua maior preocupação era dar um bebê para o mundo, provando assim sua sanidade. Agora precisava provar para ela mesma que vivia a loucura saudável da preocupação materna primária, loucura essa capaz de vinculá-la a Pedro. Esse estado de preocupação materna primária, que aparece nas últimas semanas da gestação e avança até as primeiras semanas de vida do bebê, possibilita que a mãe corresponda às necessidades corporais do seu filho e, sobretudo, permite que essas possam ser acolhidas e providas de forma satisfatória para o desenvolvimento de um sujeito rumo à independência (Winnicott, 1956/1983a).

O pequeno Pedro, nome que é sinônimo de rochedo ou pedra fundamental, precisou apenas de duas semanas para a reabilitação total. Durante esse período, o trabalho de escuta e orientação foi intenso com Betânia. Em alguns dias foram feitos três ou quatro atendimentos, alguns durando dez ou 15 minutos, outros em torno de uma hora. Estabelecemos, assim, um parâmetro de "livre demanda", termo comumente utilizado por pediatras para aconselhar as mães a oferecerem o peito apenas quando o bebê solicitar, ou seja, sem uma rotina rígida que possa angustiar tanto a mãe quanto o bebê. Pois foi assim que também "maternei" Betânia: por livre demanda. Sempre que entendíamos necessário o encontro, o fazíamos sem pressão de tempo ou rotina. Nessas sessões oferecia segurança e acolhimento, mas também explorava as questões psiquiátricas relacionadas ao seu surto, ${ }^{3}$ tais como procurar um psiquiatra, ginecologista e pediatra que a acompanhasse após a alta hospitalar de Pedro.

Muitos dos atendimentos aconteceram na própria UTIN, ao lado da incubadora do bebê. Por isso pude acompanhar o início do estabelecimento

${ }^{3}$ Não tomarei o conceito de surto no sentido nosológico do termo, não é intenção categorizar ou classificar o que Betânia vivenciou. O termo surto foi muito utilizado por Betânia nas sessões, embora o diagnóstico psiquiátrico tenha sido de Transtorno de Ansiedade. Acredito que para ela o termo 'surto' representasse um estado esporádico e transitório, o que permitia-lhe vislumbrar um futuro imediato sem a incidência desse estado, visto que estava sendo medicada. 


\section{ARTIGOS}

do vínculo entre mãe e filho, bem como os percalços que essa dupla precisou enfrentar para se entender mutualmente. Testemunhei a primeira mamada, vi Betânia aperfeiçoando suas habilidades para trocar e manusear Pedro e presenciei o constante entrosamento entre essa dupla. Ainda assim, uma preocupação deixava-me inquieta: após a alta hospitalar de Pedro, quem cuidaria de Betânia para que ela pudesse cuidar do filho?

Ao longo dos dias fomos elaborando em conjunto uma lista de profissionais que pudessem acompanhar mãe e filho: pediatra, ginecologista, psiquiatra e psicólogo. Mas para além desses profissionais, havia uma lacuna de cuidado afetivo que não poderia ser preenchida por nenhum especialista. $\mathrm{O}$ vínculo entre Pedro e Betânia estava em pleno processo de desenvolvimento, mas faltava o terceiro na relação, aquela pessoa que de alguma forma pudesse amparar essa mãe, assim como o trabalho de escuta psicanalítica me permitia fazer.

Coincidência, ou não, certo dia encontrei Betânia nos corredores do hospital acompanhada de uma mulher que logo soube ser sua mãe. Diante dessa oportunidade, sugeri que conversássemos, nós três, sobre todas as questões que envolviam a inserção de Pedro na família. A mãe de Betânia, a quem chamarei de Fátima, mostrou-se aberta a ouvir as colocações da filha sobre suas dificuldades, mas particularmente ficou muito tocada ao poder ouvi-la contar sobre suas fragilidades. Fátima ponderou o quanto sempre foi "muito dura" com Betânia e mostrou-se arrependida por não tê-la apoiado durante a gestação. Foi um encontro muito emotivo para as duas, um encontro que pôde reatar os laços de mãe e filha que talvez, em algum momento, se afrouxaram.

É importante perceber que essa possibilidade de poder retomar a relação entre mãe/avó e filha só foi possível porque, tal como era minha hipótese inicialmente, Betânia havia preservado dentro de si objetos bons. O desejo de restaurar o objeto bom internalizado é uma característica dos estados mais integrados da posição depressiva (Klein, 1936/1996a, 1937/1996b, 1957/1974). Betânia, mesmo cambaleante e ainda precisando muito ser amparada, permitiu que sua própria mãe manifestasse o desejo de estar junto a ela, em uma tentativa de reparar desavenças e intrigas de outrora. Foi transpondo a barreira de suas intensas defesas e, primeiramente, abrindo a possibilidade de ser ouvida por uma psicanalista, que ela pôde também se abrir para um contato mais íntimo com sua mãe e com o seu filho. Betânia conseguia estar minimamente integrada para aceitar o acolhimento de sua mãe, ao mesmo tempo em que também reconhecia o ataque e tentava reparar o mal que fez. Inicialmente ela não foi capaz de experimentar uma privação sem ser dominada pelo ódio. Mais tarde, a compreensão e tolerância que a 


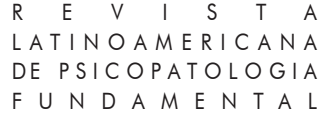

ela foram oferecidas - por mim e por toda a equipe da UTIN — puderam ser deslocadas para retomar a relação com a mãe, ao mesmo tempo em que oferecia acolhimento para o filho. Pela relação analítica foi possível restabelecer o par cuidador-cuidado, fazendo com que Betânia recuperasse o objeto bom dentro de si, pois abriu a possibilidade de aceitar se cuidada, registrar os cuidados recebidos, capacitando-se a cuidar a partir de então.

Via de regra, na UTIN, são admitidos apenas o pai e a mãe do bebê internado. Avós ou outros parentes são apenas permitidos em casos especiais. Tínhamos um caso especial, por isso, após nossa conversa, Fátima pôde conhecer seu neto. Acompanhei mãe e filha até a incubadora do bebê, mas ali não permaneci. Entendi que meu trabalho havia sido concluído; essas três gerações (avó-filha-neto) teriam um longo caminho pela frente. Acredito, porém, que estavam na rota de múltiplas reparações e estabelecendo capacidades para se cuidarem mutualmente.

\section{Sobre a escuta psicanalítica para a maternidade}

Tal como foi exposto no caso apresentado, o sentido da escuta psicanalítica é o de amparar a palavra enunciada por aquele que sofre. A comunicação entre aquele que fala - paciente - e aquele que escuta - psicanalista - pode ser marcada pela angústia que prenuncia a dor e o desespero. Diante da marca do sofrimento, muitas vezes com recursos psíquicos escassos para simbolizar o rompante da angústia, o amparo oferecido por um atendimento psicanalítico e uma escuta acolhedora tendem a transformar situações emergenciais de sofrimento em estados mais organizados e integrados.

Portanto, o atendimento psicanalítico pode ocorrer continuamente dentro de uma clínica, com periodicidade, tempo, contrato (tempo, dinheiro, enquadre), como pode acontecer apenas em um momento específico, como, por exemplo, dentro de um hospital. Assim, a configuração de um atendimento psicanalítico não está necessariamente no setting ou no enquadre analítico clássico - o que caracteriza uma situação analítica é o que está dentro (no inconsciente) e o que está entre (aquilo que se passa entre o analista e o sujeito em atendimento). A sustentação se dá pela escuta e pelo processo mental do psicanalista e do paciente, independentemente de onde, como e quando essa escuta é disponibilizada. Como nos aponta Khan (1984), 


\section{ARTIGOS}

a pessoa do psicanalista oferece receptividade para o material do paciente, ajuda a liberar e a organizar os desejos inconscientes e empresta ao paciente sua capacidade mais livre para associações simbólicas.

Será então a escuta sensível de um psicanalista aberto a acolher o sofrimento do outro o que caracterizará um atendimento psicanalítico. Para Meyer (2008), "a mente do analista é seu instrumento de trabalho" (p. 81). É pela mente do psicanalista que elementos nodais, captados pela escuta, provocarão uma ressonância tal que magnetiza e integra aspectos emocionais do paciente que até então pareciam dispersos. Uma escuta psicanalítica orientada para mulheres que acabaram de se tornar mães pode contribuir para o estabelecimento de um vínculo sadio entre mãe-bebê e, ao mesmo tempo, pode amparar e acolher o desamparo que acomete muitas mulheres, seja em situações de risco físico e psíquico para mãe e/ou bebê, ou mesmo em gestações e partos sem intercorrências puerperais ou neonatais.

A escuta psicanalítica orientada para a maternidade pode, por exemplo, amparar mães e pais na difícil situação de nascimentos prematuros ou de doenças neonatais. Não é muito difícil visualizar a dor, desespero e desamparo que acometem os familiares diante da urgência de um parto prematuro ou de bebês que nascem com algum problema de saúde. Freud nos explica que o nascimento de um filho reativa nos pais a revivescência e reprodução de seu próprio narcisismo.

Assim eles [pais] se acham sob a compulsão de atribuir todas as perfeições ao filho - o que uma observação sóbria não permitiria fazer - e de ocultar e esquecer todas as deficiências dele. (...) A doença, a morte, a renúncia ao prazer, restrições à sua vontade própria não a atingirão; as leis da natureza e da sociedade serão ab-rogadas em seu favor; ela será mais uma vez realmente o centro e o âmago da criação - 'Sua Majestade o Bebê, como outrora nós mesmos nos imaginávamos. (...) $\mathrm{O}$ amor dos pais, tão comovedor e no fundo tão infantil, nada mais é senão o narcisismo dos pais renascido, o qual, transformado em amor objetal, inequivocamente revela sua natureza anterior. (Freud, 1914/2006b, pp. 97-98)

Quando o bebê nasce prematuramente ou ainda doente, as mães sentem-se feridas em seu narcisismo, pois não podem atribuir ao filho as perfeições que outrora fantasiaram. Sentimentos de ambivalência invadem a dinâmica relacional da mãe com o seu bebê. Esse bebê que ela deveria amar é o mesmo bebê por quem sente desapontamento e consternação. "A ambivalência não está na moda e, no entanto, como encarar uma maternidade sem ambivalência, venha ela da mãe ou da equipe terapêutica?" (Mathelin, 1999, p. 13). 


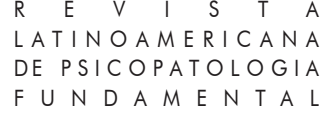

Uma escuta psicanalítica na maternidade pode oferecer um lugar "no momento em que todos preferem não ouvir, e permitir a fala, quando todos preferem calar-se" (Bernardino, Santos, Pedrali, \& Dionísio, 2012, p. 31). Por outro lado, como explicar o desamparo e a angústia materna em situações nas quais mãe e bebê estão fisicamente bem? O medo e a insegurança que seguem após o nascimento não são uma exclusividade de mães com complicações puerperais e neonatais. Como observa Mathelin (1999):

As mães falam às vezes do medo de serem destruídas, desse sentimento de serem "esvaziadas" por seu bebê. (...) Esses bebês vividos como vampiros estão para elas numa demanda sem fim que elas não conseguem saciar; e o amor apaixonado e exclusivo desse lactante por elas lhes dá o sentimento de serem devoradas por ele. Como se essa "goela aberta da vida", essa violenta força libidinal do filho se tornasse para elas insuportável. (p. 15)

Para que possamos ampliar o espectro de compreensão das questões que concernem à maternidade, particularmente nos primeiros momentos da mãe com o seu filho, temos de ultrapassar a imagem da doçura e do amor materno que são tão disseminados em nossa cultura. Winnicott (1947/2000) oferece alguns cenários que direcionam o nosso olhar para o outro lado da moeda no que concerne à maternidade:

A mãe, no entanto, odeia o seu bebê desde o início. (...) Permitam-me apresentar certos motivos pelos quais a mãe odeia o seu bebê: (...)

- O bebê interfere com a sua vida privada, é um obstáculo para a sua ocupação anterior. (...)

- Ele é impiedoso, trata-a como lixo, uma serva sem pagamento, sua escrava.

(...)

- Ele é desconfiado, recusa a comida tão boa que ela preparou e faz com que ela duvide de si mesma, mas com a tia ele come tudo. (...)

- Depois de uma manhã horrível, ela sai com ele e ele sorri para um estranho, que diz: 'Não é uma gracinha?'. (...)

- Se ela falha com ele no início, sabe que ele se vingará para sempre. (pp. 285-286)

Adicionalmente, Winnicott nos lembra com frequência que uma mãe é naturalmente boa. "Se fracassar como mãe, é que traz em si uma ferida bem mais antiga que jamais se fechou" (Mathelin, 1999, p. 16). A escuta psicanalítica oferece a possibilidade de dar voz a esses sentimentos ambivalentes e, ao mesmo tempo, apoiar a mãe para que ela possa entrar no estado de preocupação materna primária, abrandando o turbilhão de afetos deslocados, entre eles a culpa, o medo e a insegurança. Esse é o lugar do psicanalista na escuta de mulheres que se tornaram mãe. 


\section{ARTIGOS}

\section{À guisa de conclusão}

Uma escuta psicanalítica orientada para a maternidade é a via pela qual, por meio de uma escuta empática, o psicanalista se coloca presente e atuante na situação emergencial da gestação, parto, situações neonatal e puerpério, objetivando amparar, auxiliar, acolher e orientar a mulher que se torna mãe. Esse tipo de escuta é caracterizado por um vínculo breve com o psicanalista, evidenciando a prerrogativa do estabelecimento de uma relação de confiança, com foco e objetivo muito bem delineados: permitir a instauração da experiência da maternidade. É esperado que esse cuidado mais pontual possa ser internalizado e que, em momentos subsequentes de desamparo, as ressonâncias desse cuidado possam ser recuperadas dentro de cada mulher.

No caso apresentado, Betânia passou por situações de extrema fragilidade, por momentos disruptivos que, de alguma forma, poderiam ameaçar a experiência de ligação e de continência com o seu bebê. $\mathrm{O}$ que imperava neste caso era o caos, com vias a uma desorganização emocional que ameaçava a própria possibilidade de ser mãe. Betânia queria ser mãe, mas não estava em condição de sê-lo. O desejo pela maternidade estava presente, mas muitos eram os fatores, de ordem externa e interna, que impediam sua viabilização. Betânia estava convicta de que seria a maternidade que a libertaria do estigma da loucura. O desejo de ser mãe era ardente e, para concretizá-lo, colocou à prova sua própria sanidade. De fato, a maternidade se instaurou quando houve a compreensão de que ela apenas poderia cuidar de seu filho se se permitisse ser cuidada.

Para dar apoio e suporte a essas mulheres, a escuta psicanalítica para a maternidade referencia-se nos preceitos da psicanálise, amplia o campo de atuação de um psicólogo hospitalar e serve como ferramenta de apoio ao turbilhão de afetos desencontrados presentes em UTIN's e berçários. O oferecimento de uma escuta empática possibilita aos pais, especialmente à mãe, a expressão de sentimentos reprimidos ou ofuscados pela emergência da situação de risco. Na verdade, a reconstituição do par cuidador-cuidado revela que a essência do objeto bom é uma capacidade de cuidar, de se preocupar com o outro e ter uma escuta empática. Quando Betânia recebeu uma escuta empática, ela pôde também oferecer para o seu bebê um olhar e uma escuta integradoras, função primordial para a constituição do cerne da maternidade.

Para encerrar, convoco Winnicott (1966/2006) que sagazmente escreveu: "Quero dizer que não se trata de precisarmos dizer às mães o que 


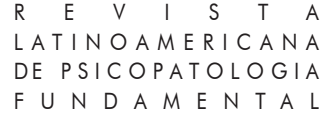

devem fazer, ou como devem ser. Se não o forem, paciência: não podemos fazer com que sejam" (p. 90). A escuta psicanalítica para a maternidade tem um valor ímpar no atendimento de mulheres que, mesmo diante das adversidades, são mães.

\section{Referências}

Bernardino, L. M. F., Santos, C. C., Pedrali, C. B. M., \& Dionísio, M. W. S. (2012). A escuta psicanaliticamente orientada em uma UTI neonatal. In M. C. M. Kupfer, L. M. F. Bernardino, \& R. M. M. Mariotto (Orgs.), Psicanálise e ações de prevenção na primeira infância (pp. 29-46). São Paulo, SP: Escuta/Fapesp.

Fontes, I., Roxo, M., Soares, M. C. S., \& Kislanov, S. (2014). Virando gente: a história do nascimento psíquico. São Paulo, SP: Ideias \& Letras.

Figueiredo, L. C. (2014). Escutas em análise / Escutas poéticas. Revista Brasileira de Psicanálise, 48(1), 123-137.

Freud, S. (2006a). Recomendações aos médicos que exercem a psicanálise. In Edição Standard Brasileira das Obras Psicológicas Completas de Sigmund Freud (pp. 123-136). Rio de Janeiro, RJ: Imago. (Trabalho original publicado em 1912).

Freud, S. (2006b). Sobre o narcisismo: uma introdução. In Edição Standard Brasileira das Obras Psicológicas Completas de Sigmund Freud (pp. 77-110). Rio de Janeiro, RJ: Imago. (Trabalho original publicado em 1914).

Freud, S. (2006c). Inibições, sintomas e ansiedade. In Edição Standard Brasileira das Obras Psicológicas Completas de Sigmund Freud (pp. 81-174). Rio de Janeiro, RJ: Imago. (Trabalho original publicado em 1926).

Hilferding, M. (1991). Reunião de 11 de janeiro de 1911: ata da sociedade psicanalítica de Viena. In M. Hilferding, T. Pinheiro, \& H. B. Vianna, As bases do amor materno (pp. 89-101). São Paulo, SP: Escuta. (Trabalho original publicado em 1911).

Khan, M. (1984). Psicanálise: teoria, técnica e casos clínicos. Rio de Janeiro, RJ: Francisco Alves.

Klein, M. (1974). Inveja e gratidão: um estudo das fontes do inconsciente. Rio de Janeiro, RJ: Imago. (Trabalho original publicado em 1957).

Klein, M. (1996a). O desmame. In Amor, culpa e reparação e outros trabalhos (pp. 330-345). Rio de Janeiro, RJ: Imago. (Trabalho original publicado em 1936).

Klein, M. (1996b). Amor, culpa e reparação. In Amor, culpa e reparação e outros trabalhos (pp. 346-384). Rio de Janeiro, RJ: Imago. (Trabalho original publicado em 1937). 


\section{ARTIGOS}

Klein, M. (1996c). O luto e suas relações com os estados maníaco-depressivos. In Amor, culpa e reparação e outros trabalhos (pp. 385-412). Rio de Janeiro, RJ: Imago. (Trabalho original publicado em 1940).

Lima, G. G. (2006). Da mãe a mulher: os circuitos do amor, desejo e gozo. Tese de doutorado, Psicologia Escolar e do Desenvolvimento Humano, Instituto de Psicologia, Universidade de São Paulo, São Paulo, SP.

Mathelin, C. (1999). O sorriso da Gioconda: clínica psicanalítica com os bebês prematuros. Rio de Janeiro, RJ: Companhia de Freud.

Meyer, L. (2008). Rumor na escuta: ensaios de psicanálise. São Paulo, SP: Ed. 34.

Winnicott, D. W. (1983a). A preocupação materna primária. In Da pediatria à psicanálise: obras escolhidas (pp. 399-405). Rio de Janeiro, RJ: Imago. (Trabalho original publicado em 1956).

Winnicott, D. W. (1983b). A integração do ego no desenvolvimento da criança. In $O$ ambiente e os processos de maturação: estudos sobre a teoria do desenvolvimento emocional (pp. 55-61). Porto Alegre, RS: Artes Médicas. (Trabalho original publicado em 1962).

Winnicott, D. W. (1983c). Os doentes mentais na prática clínica. In $O$ ambiente e os processos de maturação: estudos sobre a teoria do desenvolvimento emocional (pp. 196-206). Porto Alegre, RS: Artes Médicas. (Trabalho original publicado em 1963).

Winnicott, D. W. (1984). Consultas terapêuticas em psiquiatria infantil. Rio de Janeiro, RJ: Imago. (Trabalho original publicado em 1971).

Winnicott, D. W. (1989). O conceito de indivíduo saudável. In Tudo começa em casa (pp. 3-22). São Paulo, SP: Martins Fontes. (Trabalho original publicado em 1971).

Winnicott, D. W. (2000). O ódio na contratransferência. In Da pediatria à psicanálise: obras escolhidas (pp. 277-287). Rio de Janeiro, RJ: Imago. (Trabalho original publicado em 1947).

Winnicott, D. W. (2006). Os bebês e suas mães. São Paulo, SP: Martins Fontes, 2006. (Trabalho original publicado em 1966).

\section{Resumos}

(Giving support to women who become mothers: Psychoanalytic listening)

The purpose of this paper is to present a listening model for issues involving motherhood. In order to establish this psychoanalytical listening place within an institutional scope, it was initially necessary to broaden the understanding of the vicissitudes inherent to being a mother. A method based on support was used to offer 


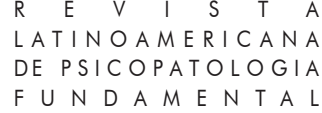

care to women whose babies were hospitalized in a Neonatal Intensive Care Unit (NICU). Based on this case, it was possible to present a listening model that is based on psychoanalytical references, but which, at the same time, expands the traditional psychoanalysis model.

Key words: Psychoanalytic listening, motherhood, mother-baby relationship, case presentation

(Support et accueil de femmes qui deviennent mères: une écoute psychanalytique)

Le but de cet article est de présenter un modèle d'écoute par rapport aux questions liées à la maternité. Pour établir cet espace institutionnel d'écoute psychanalytique, il s'est avéré nécessaire, initialement, d'élargir la compréhension des vicissitudes du processus qui entraîne être mère. Une méthode basée sur le support et l'accueil des mères dont les nouveau-nés étaient internés dans l'Unité de Thérapie Intensive Néo-natale (UTIN) à été utilisée. C'est sur la base de cette étude qu'il fut possible de modéliser l'écoute sous l'angle psychanalytique, tout en élargissant le modèle traditionnel de la psychanalyse.

Mots clés: Écoute psychanalytique, maternité, relation mère-nouveau-né, étude de cas

(Apoyo y recepción a las mujeres que se convierten madres: una escucha psicoanalítica)

La propuesta de este articulo es presentar un modelo de escucha dirigido a las cuestiones relacionadas a la maternidad. Para construir este espacio de escucha psicoanalítica en el ámbito institucional, fue necesario inicialmente ampliar la comprensión de las vicisitudes implicadas en el proceso de ser madre. Un método respaldado en el amparo y en el acogimiento fue el modelo utilizado para atender a las mujeres que tenían a sus bebés internados en la Unidad de Cuidados Intensivos Neonatales (UCIN). A partir del caso expuesto, fue posible presentar un modelo de escucha que se fundamenta en el referencial psicoanalítico, pero que, al mismo tiempo, amplía el modelo tradicional del psicoanálisis.

Palabras clave: Escucha psicoanalítica, maternidad, relación madre-bebé, presentación de caso

(Unterstüetzung und Beratung für werdende Müetter: psychoanalytisches Zuhören)

Dieser Artikels stellt ein Modell des Zuhörens in Bezug auf Fragen zur Mutterschaft vor. Um diesen psychoanalitischen Raum des Zuhörens im institutionellen Bereich aufzubauen war es anfangs nötig, das Verständnis zu den Einzelheiten des Prozesses der Mutterschaft zu erweitern. Eine Methode, die auf 


\section{ARTIGOS}

Unterstützung und Aufnahme gegründet ist, wurde als Modell benutzt, um Frauen, deren Kinder in der Intensivstation für Neugeborene hospitalisiert waren, zu betreuen. Der dargelegte Fall erlaubte es uns, ein Hörmodell vorzustellen, das auf psychoanalytische Referenzen basiert, das aber gleichzeitig über das traditionelle Modell der Psychoanalyse hinausgeht.

Schlüsselwörter: Psychoanalytischer Raum des Zuhörens; Mutterschaft; Mutter-

Kleinkind Beziehung; Erläuterung eines Falles

（支持和接受女人成为母亲: 对产妇的心理倾听）

本文目的是针对产妇提出一个倾听模式。爲了建立这个心理倾听空间，首 先需要扩展我们对於当母亲的复杂的心理变化过程之理解。目前使用的方法是 对新生婴儿重症监护室里 (UTIN) 的母亲进行心理支持。借由现有的案例, 作者 提出一个心理分析方面的倾听模式, 同时也扩展了传统的心理分析学模型。

关键词：心理分析倾听，妇产科，母亲与贞儿的关系，案例介绍

Citação/Citation: Prata, A. K A. V. \& Cintra, E. M. de U. (2017, março). Apoio e acolhimento à mulher que se torna mãe: uma escuta psicanalítica. Revista Latinoamericana de Psicopatologia Fundamental, 20(1), 34-50.

Editores do artigo/Editors: Profa. Dra. Ana Maria Rudge e Profa. Dra. Sonia Leite

Recebido/Received: 16.9.2016 / 9.16.2015 Aceito/Accepted: 19.11.2016 / 11.19.2016

Copyright: (C) 2009 Associação Universitária de Pesquisa em Psicopatologia Fundamental/ University Association for Research in Fundamental Psychopathology. Este é um artigo de livre acesso, que permite uso irrestrito, distribuição e reprodução em qualquer meio, desde que o autor e a fonte sejam citados / This is an open-access article, which permits unrestricted use, distribution, and reproduction in any medium, provided the original authors and sources are credited. 


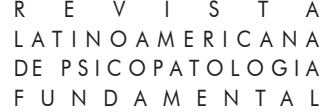

Financiamento/Funding: Pesquisa financiada pelo Conselho Nacional de Desenvolvimento Científico e Tecnológico - CNPq / Research funded by Conselho Nacional de Desenvolvimento Científico e Tecnológico - CNPq.

Conflito de interesses/Conflict of interest: As autoras declaram que não há conflito de interesses / The authors have no conflict of interest to declare.

\section{Alcimeri Kühl Amaral Veiga Prata}

Mestre em Psicologia Clínica pela Pontifícia Universidade Católica de São Paulo - PUC/ SP (São Paulo, SP, Br).

Rua Gulhot Rodrigues, 145/309 - Campos Elíseos

27542-040 Resende, RJ, Br.

alcimeriprata@hotmail.com

\section{Elisa Maria de Ulhoa Cintra}

Psicanalista; Professora da Faculdade de Ciências Humanas e da Saúde da Pontifícia Universidade Católica de São Paulo - PUC-SP (São Paulo, SP, Br) e do Programa de Estudos de Pós de Psicologia Clínica da mesma universidade.

Rua Monte Alegre, 984 - Perdizes

05014-901 São Paulo, SP, Br.

emcintra@pucsp.br

This is an open-access article, which permits unrestricted use, distribution, and reproduction in any medium for non-commercial purposes provided the original authors and sources are credited. 